- ACORN Australan college of | JOURNAL OF PERIOPERATIVE NURSING

Volume 31 | Issue 2

Article 1

6-1-2018

\title{
Changing the standard of blood management in Australia: An overview
}

Follow this and additional works at: https://www.journal.acorn.org.au/jpn

Part of the Health Services Administration Commons, Health Services Research Commons, Perioperative, Operating Room and Surgical Nursing Commons, and the Surgery Commons

(c) (7)

This work is licensed under a Creative Commons Attribution 4.0 License.

\section{Recommended Citation}

Delaforce, Alana; Duff, Jed; and Ralph, Nicholas (2018) "Changing the standard of blood management in Australia: An overview," Journal of Perioperative Nursing: Vol. 31 : Iss. 2 , Article 1.

Available at: https://doi.org/10.26550/2209-1092.1026

https://www.journal.acorn.org.au/jpn/vol31/iss2/1

This Article is brought to you for free and open access by Journal of Perioperative Nursing. It has been accepted for inclusion in Journal of Perioperative Nursing by an authorized editor of Journal of Perioperative Nursing. 


\section{Authors}

\section{Alana Delaforce}

School of Nursing and Midwifery,

University of Newcastle, Australia

Associate Professor Jed Duff

School of Nursing and Midwifery,

University of Newcastle, Australia

Associate Professor Nicholas Ralph Centre for Population Health, University

of Southern Queensland, Australia

\section{Corresponding author}

Alana Delaforce

School of Nursing and Midwifery,

University of Newcastle, Australia

alanasarah@hotmail.com

\section{Changing the standard of blood management in Australia: An overview}

\section{Introduction}

In 2012 the Patient Blood Management (PBM) guidelines were published by the National Blood Authority ${ }^{1}$, providing a standard of practice for clinicians across Australia. The Australian Commission on Safety and Quality in Health Care (ACSQHC) standards were recently updated in $2017^{2}$ and the adoption of the PBM guidelines will now be nationally mandated for hospitals in 2019. In this article, we answer three questions:

1. Why were the PBM guidelines developed?

2. What do the PBM guidelines recommend?

\section{How can we implement the PBM guidelines successfully?}

Keywords: patient blood management, blood safety, blood transfusion, perioperative care, perioperative nursing

Our principal aim in addressing these questions is to raise awareness among perioperative nurses of the need to comply with PBM guidelines as an essential component of safe and effective practice.

\section{Why were the PBM guidelines developed?}

After a study was conducted in 1999 by Hébert et al. which demonstrated that giving transfusions was negatively impacting patient outcomes, clinicians started to question the safety of transfusions. The results of this study promoted further clinical research which has since linked blood transfusions to a number of adverse outcomes including febrile reactions, coagulopathies, fluid overload causing both acute lung and kidney injury, iron overload and immunomodulation ${ }^{4,5}$. Eventually, there was enough evidence to support the need for the formation of a government body to help regulate patient blood management, and the National Blood Authority (NBA) was the result of this. The National Blood Authority (NBA) established guidelines in 2012 to help facilitate safe blood management practice in the context of increased adverse outcomes and poor compliance with recommended administration practice $^{1,6,7}$.

The current PBM guidelines aim to help clinicians make decisions to prepare patients pre-operatively, carry out intraoperative interventions to minimise blood loss, and improve the post-operative management of any anaemia present ${ }^{8-10}$. PBM guidelines can result in significant clinical and cost benefits with Farmer et al.11 finding that a Western Australian initiative resulted in the rate of issuance of red blood cells dropping from 318 to 194 per 1000 discharges, with a saving of \$18.5 million for product-related costs only ${ }^{11}$. This figure increased to over $\$ 80$ million for transfusion-related activity. 


\section{What do the PBM guidelines recommend?}

The focus of the original version of the ACSQHC standards has been on blood products and their storage, and administration safety 4 . It is now moving towards a patientcentric approach that focuses on prevention and preparation $99,2,1,4,5$. The assessment of blood requirements should be patient-centric, rather than product-centric'. The 'threepillar' approach forms the basis of blood management according to the PBM guidelines ${ }^{16}$. This approach can be broadly mapped to the new requirements of the $A C S Q H C$ standard 'Blood management'.

\section{Preparation of patients preoperatively}

This component of the PBM guidelines recommends that patients should be referred for blood screening as soon as the decision to have surgery is made ${ }^{1,6}$. If the patient is anaemic, a thorough investigation needs to be undertaken to identify potential causes ${ }^{9,1778}$. If the reason is an absolute iron deficiency, iron is administered, either orally or intravenously, to restore iron levels before surgery. If there is an underlying cause of iron deficiency, efforts should be made to address it?

The intra-operative minimisation of blood loss and conservation of the patient's blood

The PBM guidelines outline that the patient's blood is a precious, lifesaving resource, and every effort should be made to minimise loss and conserve supply?. Meticulous surgical haemostasis, pharmacological adjuvants and, in cases where significant blood loss is expected (>500 ml), cell saving machines should be utilised ${ }^{9,15}$.
Optimising physiological tolerance to anaemia

This component of the guidelines involves two key recommendations:

1. keeping the patient warm

2. assuring adequate oxygenation.

Blood loss impacts the patient's ability to thermoregulate and keeping them warm helps the body return to normal function ${ }^{12}$. Ensuring appropriate supplemental oxygen is available and utilised assists in offsetting the lowered ability of the blood to carry a sufficient supply ${ }^{12}$.

\section{How can we implement the PBM guidelines successfully?}

To meet the ACSQHC standards, providers will need to ensure compliance with PBM guideline statements across their clinical governance systems, clinical use of blood and blood products, and availability and safety of blood and blood products. Implementing the PBM guidelines should result in reduced blood transfusions and adverse patient outcomes associated with blood management ${ }^{2,3,19}$. Several enablers of implementation are suggested by the PBM guidelines including patient and clinician education, establishing a blood management coordinator, monitoring of local policies and procedures ${ }^{13,20}$, use of decision-support tools for clinicians, and event reporting.

\section{Conclusion}

Hospitals will need to ensure that adequate clinical governance systems are in place before 2019 when the new standard takes effect. Implementing PBM guidelines will have implications for perioperative nurses. Preoperative screening for anaemia in preoperative clinics, assisting with developing and enacting PBM management plans for patients, and following up on patients to ensure optimal surgical outcomes is a true perioperative role. As a profession, perioperative nurses should have a more active role in PBM management. ACORN should consider endorsing the guidelines and explore whether they could practically support them through the careful integration of PBM principles into relevant standards.

\section{References}

1. National Blood Authority (NBA) and National Health Medical Research Council (NHMRC). Patient blood management guidelines: Module 2 - Perioperative. Canberra: NBA, 2012.

2. Australian Commission on Safety \& Quality in Health Care (ACSQHC). National Safety and Quality Health Service Standards 2nd ed. Sydney: ACSQHC, 2017.

3. Hébert PC, Wells G, Blajchman MA, Marshall J, Martin C, Pagliarello G et al. A multicenter, randomized, controlled clinical trial of transfusion requirements in critical care. $\mathrm{N}$ Engl J Med 1999;340(6):409-417.

4. Isbister JP, Shander A, Spahn DR, Erhard J, Farmer SL, Hofmann A. Adverse blood transfusion outcomes: Establishing causation. Transfus Med Rev 2011;25(2):89-101.

5. Ismail S. Hazards and limitation of perioperative transfusion: Need to adopt blood transfusion guidelines. Anaesthesia, Pain \& Intensive Care 2016;20:S86-S90.

6. Leahy MF, Mukhtar SA. From blood transfusion to patient blood management: A new paradigm for patient care and cost assessment of blood transfusion practice. Intern Med J 2012;42(3):332-338.

7. Hofmann A, Farmer S, Towler SC. Strategies to preempt and reduce the use of blood products: An Australian perspective. Curr Opin Anaesthesiol 2012;25(1):66-73.

8. Goodnough LT. Patient blood management Anesthesiology 2012;116(6):1367-1376.

9. Isbister JP. The three-pillar matrix of patient blood management. ISBT Sci Ser 2015;10:286-294.

10. Meybohm P, Fischer DP, Herrmann E, Geisen C, Müller MM, Seifried E, et al. Safety and effectiveness of a patient blood management programme in surgical patients - the study design for a multicentre epidemiological non-inferiority trial by the German PBM network. ISBT Sci Ser 2015;10:141-145.

11. Farmer SL, Towler SC, Leahy MF, Hofmann A. Drivers for change: Western Australia Patient Blood Management Program (WA PBMP), 
World Health Assembly (WHA) and Advisory Committee on Blood Safety and Availability (ACBSA). Best Pract Res Clin Anaesthesiol 2013;27(1):43-58.

12. Seeber $P$, Shander A. Basics of blood management. 2nd ed. Hoboken: John Wiley \& Sons; 2012.

13. Meybohm P, Richards T, Isbister J, Hofmann A, Shander A, Goodnough LT et al. Patient blood management bundles to facilitate implementation. Transfus Med Rev 2017;31(1):62-71.

14. Eeles A, Baikady RR. Perioperative blood management. Indian J Anaesth 2017;61(6):456-462.
15. Shander A, Javidroozi M, Perelman S, Puzio T, Lobel G. From bloodless surgery to patient blood management. Mt Sinai J Med 2012;79(1):56-65.

16. Gombotz H. Patient blood management: A patient-orientated approach to blood replacement with the goal of reducing anemia, blood loss and the need for blood transfusion in elective surgery. Transfus Med Hemother 2012;39(2):67-72.

17. Murphy MF, Goodnough LT. The scientific basis for patient blood management. Transfus Clin Biol 2015;22(3):90-96.

18. Kopanidis P, Hardidge A, McNicol L, Tay S, McCall P, Weinberg L. Perioperative blood management programme reduces the use of allogenic blood transfusion in patients undergoing total hip and knee arthroplasty. J Orthop Surg Res 2016;11:28.

19. So-Osman C, Wal DE, Allard S. Patient blood management initiatives on a global level: The results of an International Society of Blood Transfusion survey. ISBT Sci Ser 2017 12(3): p. 327-335.

20. Bielby L, Akers C, Francis S, Darby S, Campbell $L$, Hollis $L$ et al. The role of the transfusion safety coordinator in Australia. ISBT Sci Ser 2016;11:118-1125. 